\title{
EISCAT observational results during the DELTA campaign
}

\author{
S. Nozawa ${ }^{1}$, Y. Ogawa ${ }^{1}$, A. Brekke ${ }^{2}$, T. Tsuda ${ }^{1}$, C. M. Hall ${ }^{2}$, H. Miyaoka ${ }^{3}$, J. Kurihara ${ }^{4}$, T. Abe ${ }^{4}$, and R. Fujii ${ }^{1}$ \\ ${ }^{1}$ Solar-Terrestrial Environment Laboratory, Nagoya University, Japan \\ ${ }^{2}$ Faculty of Science, University of Troms $\phi$, Norway \\ ${ }^{3}$ National Institute Polar Research, Japan \\ ${ }^{4}$ Institute of Space and Astronautical Science, Japan Aerospace Exploration Agency, Japan
}

(Received January 16, 2006; Revised May 2, 2006; Accepted May 15, 2006; Online published September 29, 2006)

\begin{abstract}
This paper aims at describing the ionospheric conditions during the DELTA (Dynamics and Energetics of the Lower Thermosphere in Aurora) campaign period based on EISCAT radar observations conducted at Troms $\emptyset$ $\left(69.6^{\circ} \mathrm{N}, 19.2^{\circ} \mathrm{E}\right)$. We conducted EISCAT UHF radar observations on December 5 and from December 8 to December 13, 2004 with a beam-scanning mode for a total of 74 hours. Except for December 8 during a 2 hr interval operation, we operated the EISCAT UHF radar for 12 hour intervals everyday to make it possible to derive semidiurnal tidal amplitudes and phases in the lower thermosphere. Observed electron densities and derived electric fields by the EISCAT UHF radar indicate that magnetospheric activity was high during the period from December 5 to 13 except for the night of December 13. Derived semidiurnal amplitudes during December 9-12, 2004 exhibited a day to day variation at and below $110 \mathrm{~km}$, while the corresponding phase was relatively stable over the four days except for the zonal component on December 12. Neutral and electron temperatures measured by the DELTA rocket were compared with neutral/ion and electron temperatures from the EISCAT UHF radar observations. Comparison of neutral/ion temperatures show some agreement, while poor agreements were found for the electron temperature. Possible causes of the discrepancy are discussed.
\end{abstract}

Key words: EISCAT, Troms $\emptyset$, day-to-day variability, semidiurnal tide, neutral temperature, electron temperature.

\section{Introduction}

Large-scale atmospheric circulation in the thermosphere has been investigated by modeling studies and satellite observations. However, our understanding of the wind dynamics in the lower thermosphere at high latitudes is still limited, although it is understood that the neutral atmosphere plays an important role in the magnetosphereionosphere-thermosphere coupling process. During the last two decades, by using Incoherent Scatter (IS) radars such as Chatanika $\left(65^{\circ} \mathrm{N}\right)$, Søndre Strømfjord $\left(67^{\circ} \mathrm{N}, 51^{\circ} \mathrm{W}\right)$ and EISCAT (Tromsø: $69.6^{\circ} \mathrm{N}, 19.2^{\circ} \mathrm{E}$ ), a better understanding of the lower thermosphere has been steadily advanced (e.g., Brekke et al., 1973; Johnson et al., 1987; Azeem and Johnson, 1997; Nozawa and Brekke, 1999).

Based on 56 days of EISCAT data sets Nozawa and Brekke (1999) presented the seasonal and solar cycle variations of mean wind and diurnal and semidiurnal tidal winds at Troms $\varnothing$. In their studies, they showed that the diurnal tide is weak in winter season in the lower thermosphere, while the semidiurnal tide is dominant over the height region (95-120 km). Nozawa et al. (2005) analyzed eight consecutive days of wind data obtained from November 11 to 19, 2003 at two locations of Troms $\varnothing$ and Longyearbyen $\left(78.2^{\circ} \mathrm{N}, 16.0^{\circ} \mathrm{E}\right)$, and evaluated the importance of the iondrag effect on the neutral wind dynamics. They demonstrated that the ion-drag effect started playing a role at and

Copyright (c) The Society of Geomagnetism and Earth, Planetary and Space Sciences (SGEPSS); The Seismological Society of Japan; The Volcanological Society of Japan; The Geodetic Society of Japan; The Japanese Society for Planetary Sciences; TERRAPUB. above $107 \mathrm{~km}$ at Troms $\varnothing$ when the electron density was high and the electric field was strong. They also showed that the quasi-2 day wave was attenuated in the upper mesosphere and could not penetrate into the lower thermosphere.

Strong winds and wind shears have been reported by recent studies based on rocket measurements at high latitudes (Larsen et al., 1997) and lower latitudes (Larsen et al., 1998; Yamamoto et al., 1998). However, the cause of the wind structure particularly in the vertical direction is unclear. Auroral and tidal forcing processes are thought to be important (cf. Parish et al., 2003). Simultaneous observations of the neutral atmospheric temperature, the neutral wind, and the auroral energy input are necessary for further understanding the thermospheric response to the auroral disturbance. This is one of the objectives of the Dynamics and Energetics of the Lower Thermosphere in Aurora (DELTA) campaign. Abe et al. (2006a, this issue) give an overview of the campaign objectives and the suite of instruments involved in the experiments.

During the DELTA rocket campaign, we conducted the EISCAT UHF radar observations at Troms $\varnothing$ (Folkestad et al., 1983) to monitor ionospheric conditions. The near realtime display of the EISCAT radar data at the launch site at Andenes $\left(69.3^{\circ} \mathrm{N}, 16.22^{\circ} \mathrm{E}\right)$ was actually used to indicate suitable launch conditions for the DELTA rocket. In this paper, in particular, we focus on the following two subjects of research: (1) the day to day variability of the semidiurnal tide, (2) a comparison of rocket measured neutral and electron temperatures with those of EISCAT observations. In Section 2, a descriptive overview of the data sets and the 

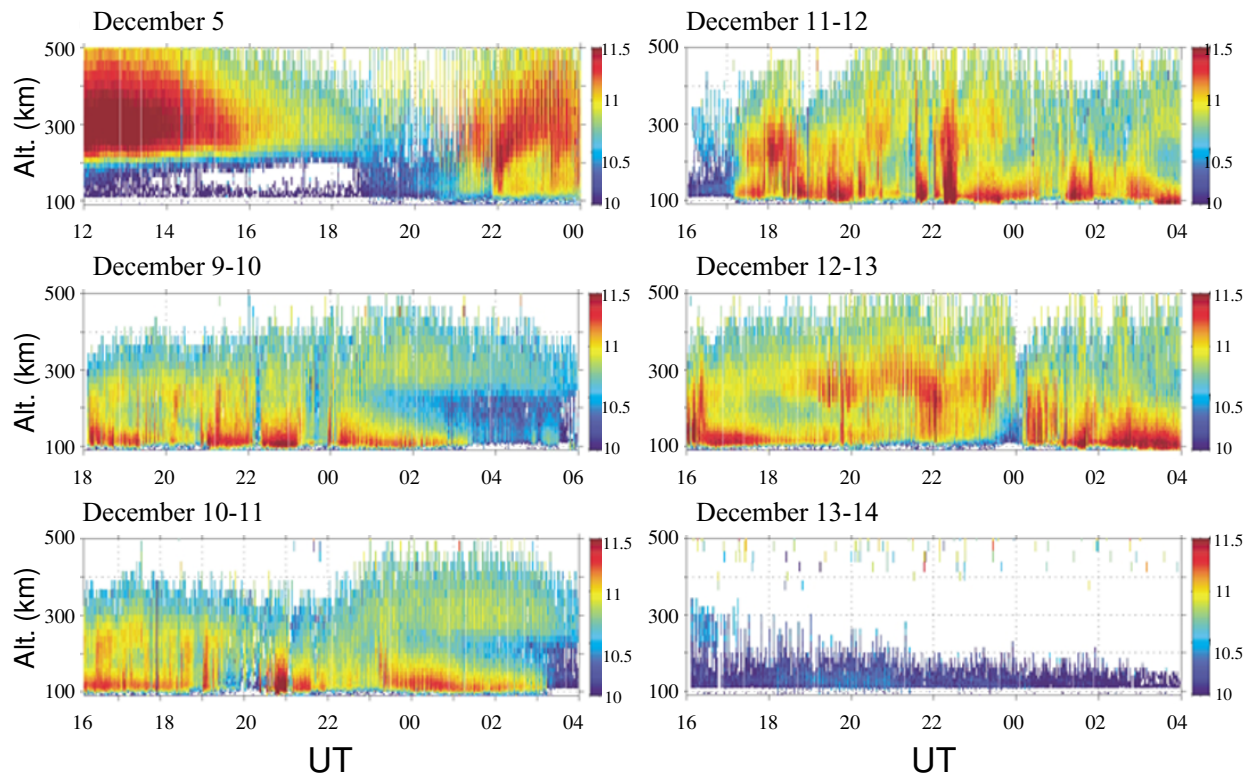

Fig. 1. Temporal and altitude variations of the electron density for 6 nights observed by the EISCAT UHF radar during the Delta campaign. Each experiment has $12 \mathrm{hr}$ intervals. UT is used. Color scale is the same for all the plots.

Table 1. Summary of EISCAT CP2 observations during the DELTA campaign in December 2004.

\begin{tabular}{cccc}
\hline Day & Start time (UT) & End time (UT) & Length of operation (hrs) \\
\hline 5 th & 12 & 24 & 12 \\
8 th & 19 & 21 & 2 \\
9 th & 18 & 06 & 12 \\
10 th & 16 & 04 & 12 \\
11 th & 16 & 04 & 12 \\
12 th & 16 & 04 & 12 \\
13 th & 16 & 04 & 12 \\
\hline
\end{tabular}

analysis is given. In Section 3, observational results of the electric field and neutral wind are presented. In Section 4, the day to day variability of the semidiurnal tide is discussed and the neutral and electron temperatures are compared. A summary is given in Section 5.

\section{Data and Data Analysis}

We conducted the EISCAT radar observations on December 5 and from December 8 to December 13, 2004 with a beam-scanning mode (i.e., Common Program 2 mode: CP2 mode). Table 1 summarizes the EISCAT radar observations. In total we operated the EISCAT UHF radar for $74 \mathrm{hrs}$ under collaborations with the EISCAT associate countries such as Sweden, Germany, U.K., Norway and Finland. From 1000 UT on December 6 to 1400 UT on December 9, 2004, a Common Program 3 (CP3) (Collis, 1995) experiment was conducted with the EISCAT UHF radar because of a World Day campaign except for a $2 \mathrm{hr}$ interval break for our experiment occurring from 1900 to 2100 UT on December 8. The CP3 observations were also used for the consideration of the rocket launch. In the CP2 mode the line of sight of the combined transmitter and receiver antenna was pointed into four consecutive positions, including one fieldaligned position, with a dwell time of $\sim 1 \mathrm{~min}$ in each posi- tion, making a six-minute full-cycle time of the antenna. We thus derived 3-D ion velocity vectors every $6 \mathrm{~min}$ from $\sim 90$ $\mathrm{km}$ up to $\sim 500 \mathrm{~km}$. Except for the operation on December 8 (2 hr interval operation), we operated the EISCAT UHF radar with the $\mathrm{CP} 2$ mode for a 12 hour interval everyday to make it possible to derive semidiurnal tidal amplitudes and phases. The EISCAT operations went well without any serious problems.

Figure 1 shows the temporal and altitude $(90-500 \mathrm{~km})$ variation of the observed electron density for six $12 \mathrm{hr}$ interval experiments conducted on December 5, 9, 10, 11, 12 and 13, 2004. On December 5, the operation started at 1200 UT, thus the high electron density was maintained by solar ionization during the day time. The electron density was low after $\sim 1700 \mathrm{UT}$, but it was again high at $\sim 2100 \mathrm{UT}$ and lasted at least until the end of the operation. On the other hand, the operation started at 1800 UT on December 9 and at 1600 UT on December 10, 11, 12, and 13. High electron density was observed over the four nights from December 9 to 12 until 0300-0400 UT every night. The CP3 observations made from December 6 to 9 showed similar features in which the electron density was high at night and in the early morning. These high electron were caused by auroral particle precipitations. We monitored the ionospheric conditions on a real-time basis for the decision of when to launch the rocket, and the launch finally occurred at 0033:00 UT on December 13, 2004. The ionosphere was extremely quiet during the next night (i.e., December 13-14).

By combining 3 sets of lines of sight velocity at each cycle, we derived a 3-D ion velocity vector from 90 to $\sim 500 \mathrm{~km}$ with different altitude resolutions: about 3-5 km from 90 to $120 \mathrm{~km}$ and about $20-30 \mathrm{~km}$ in the $F$ region. Assuming that the $F$ region plasma drifts perpendicularly to the geomagnetic field $\mathbf{B}$ solely due to the electric field $\mathbf{E}$, this field can be obtained by:

$$
\mathbf{E}=-\left(\mathbf{v}_{F} \times \mathbf{B}\right)
$$



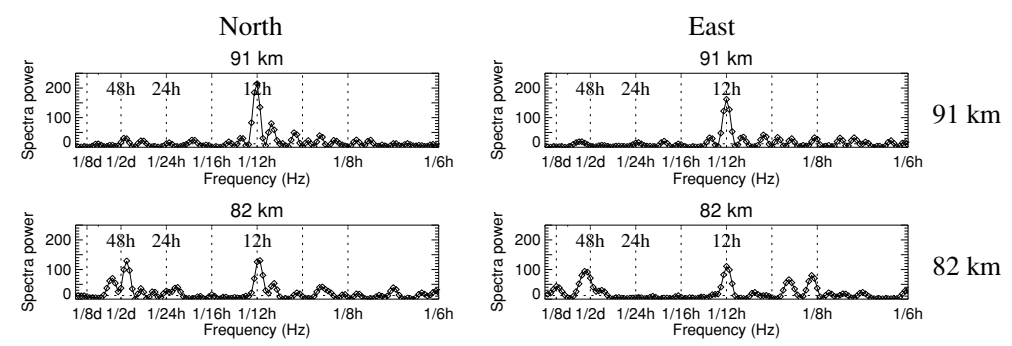

Fig. 2. Spectra of normalized spectral power of mesospheric wind data obtained with the Troms $\emptyset$ MF radar at $91 \mathrm{~km}$ (top) and $82 \mathrm{~km}$ (bottom) are shown for meridional (left) and zonal (right) components. Horizontal broken lines denote 99\% significance levels.

where $\mathbf{v}_{F}$ is the ion velocity vector in the $F$ region (data at $282 \mathrm{~km}$ are used in this study). For $\mathbf{B}$ we use the International Geomagnetic Reference Field (IGRF) model (IAGA Division I working Group 1, 1987).

Using the ion velocity vectors and the electric field vectors together with model atmospheric densities and collision frequencies, we derived neutral wind velocity vectors in the lower thermosphere between 95 and $120 \mathrm{~km}$. Thus, we derived semidiurnal tidal amplitude and phase values based on the EISCAT data during the DELTA campaign. The derivation of the neutral wind velocity in the lower thermosphere is founded on knowledge of how it is related to the ion velocity and the electric field in that region. This idea was first introduced by Brekke et al. (1973), thoroughly evaluated by Comfort et al. (1976) and later revised by Rino et al. (1977), and has since been used by a string of other authors (see Nozawa and Brekke 1999, and reference therein). According to Rino et al. (1977) the steady state ion mobility equation can be solved for the neutral wind velocity vector $\mathbf{u}$ in the following way:

$$
\mathbf{u}=\mathbf{v}-\frac{\Omega_{i}}{B v_{i n}}(\mathbf{E}+\mathbf{v} \times \mathbf{B})
$$

where $v_{i n}$ is ion-neutral collision frequency, $\Omega_{i}\left(=e B / m_{i}\right)$ is the gyrofrequency of the ions, $e$ is the elementary charge $\left(=1.602 \times 10^{-19} \mathrm{C}\right), m_{i}(=30.5 \mathrm{amu})$ is the mean ion mass, and $B$ is the magnitude of $\mathbf{B}$. The model neutral atmosphere used for calculating $v_{i n}$ is the MSIS90 model (Hedin, 1991), and the formula for the ion-neutral collision frequency is that given by Schunk and Walker (1973). With these models $\Omega_{i}$ is found equal to $v_{i n}$ at $121 \pm 0.5 \mathrm{~km}$ altitude under all conditions. There is not yet a consensus for the choice of the model for the ion-neutral collision frequency, and therefore it is possible that it can introduce uncertainties to the derived wind velocities at the uppermost heights (e.g., Johnson and Virdi, 1991; Williams and Virdi, 1989). The MF radar co-located at the EISCAT Troms $\varnothing$ site (Hall, 2001) observed continually the horizontal mesospheric wind (70$91 \mathrm{~km}$ ) with $3 \mathrm{~km}$ altitude and 5 min temporal resolutions. By combining two sets of radar wind data, we obtained altitude profiles of horizontal wind velocities from 70 to 120 $\mathrm{km}$.

Table 2 summarizes daily $A p$ indices and the solar 10.7 $\mathrm{cm}$ flux indices $\left(F_{10.7}\right)$ during the campaign period. At Troms $\emptyset$, local time (LT) is $1 \mathrm{hr}$ ahead of Universal time (UT) (i.e., LT $=\mathrm{UT}+1 \mathrm{hr}$ ), and Magnetic Local time (MLT) is $\sim 2.5 \mathrm{hrs}$ ahead of UT (i.e., MLT $=\mathrm{UT}+2.5 \mathrm{hrs}$ ).
Table 2. Summary of $A p$ and $F_{10.7}$ index during the DELTA campaign in December 2004.

\begin{tabular}{rcc}
\hline Day & Dairy $A p$ & $F_{10.7}\left(\mathrm{~W} / \mathrm{m}^{2} \mathrm{~Hz}\right)$ \\
\hline 5th & 9 & 93.1 \\
6th & 21 & 90.4 \\
7th & 15 & 87.1 \\
8th & 11 & 93.6 \\
9th & 8 & 84.7 \\
10th & 10 & 82.3 \\
11th & 15 & 87.1 \\
12th & 29 & 87.7 \\
13th & 10 & 87.0 \\
\hline
\end{tabular}

\section{Results}

Figure 2 illustrates the spectra of the mesospheric wind observed by the colocated Troms $\emptyset$ MF radar for the meridional (left) and zonal (right) components at two heights of $91 \mathrm{~km}$ (top) and $82 \mathrm{~km}$ (bottom). Wind data obtained during eight consecutive day intervals from 1200 UT on December 8 to 1200 UT on December 16, 2004 are used for calculation in order to determine the behavior of the quasi-2 day (Q2DW) wave together with the tides. This figure clearly illustrates that the semidiurnal tide is dominant at $91 \mathrm{~km}$. At $82 \mathrm{~km}$, in addition to the semidiurnal tide, Q2DW and a few waves with shorter periods between 8 and $10 \mathrm{hr}$ are identified. (It is beyond our scope to study the waves with shorter periods in this paper.) Furthermore, the previous studies by Nozawa and Brekke (1999) and Nozawa et al. (2005) showed that the semidiurnal tide is dominant in the lower thermosphere in winter. We therefore assume that the diurnal tidal component is not important during the DELTA campaign period. Figure 3 illustrates variations of the derived horizontal wind velocities for 7 heights from $98 \mathrm{~km}$ to $120 \mathrm{~km}$ from 1600 UT on December 12 to 0400 UT on December 13, 2004. Associated smoothed curves (blue color) are composed of the mean wind, and semidiurnal, $8 \mathrm{hr}$ and $6 \mathrm{hr}$ components. At and below $101 \mathrm{~km}$, data gaps occurred more seriously than those above $101 \mathrm{~km}$ because of low electron density at these heights. These data, thus, are removed when we present the altitude profile of the semidiurnal tide. Fitting curves with mean, $12 \mathrm{hr}, 8 \mathrm{hr}$ and $6 \mathrm{hr}$ components appear to be good at and above $104 \mathrm{~km}$. Rapid or scattered temporal variations of the wind velocities are found approximately between 2100 and 0200 UT. Possible causes would be gravity waves and/or uncertainties of the measurements. As we mentioned, the CP2 (i.e., monostatic 

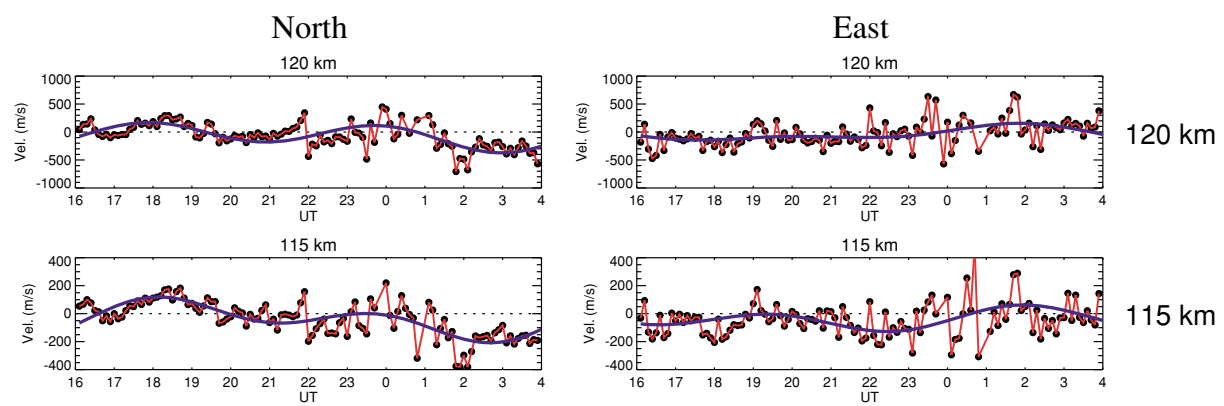

$115 \mathrm{~km}$
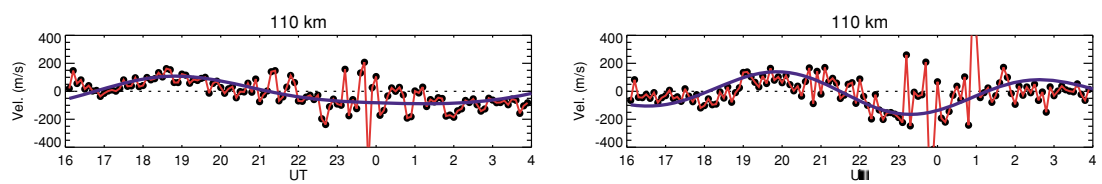

$110 \mathrm{~km}$
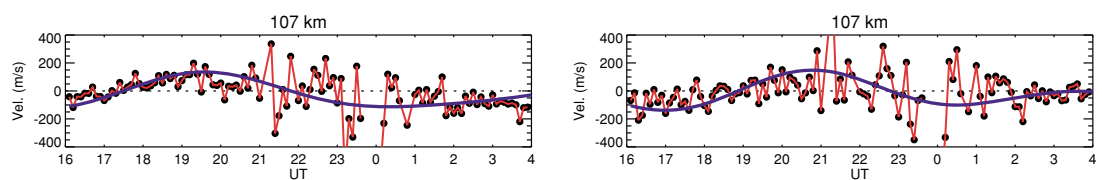

$107 \mathrm{~km}$
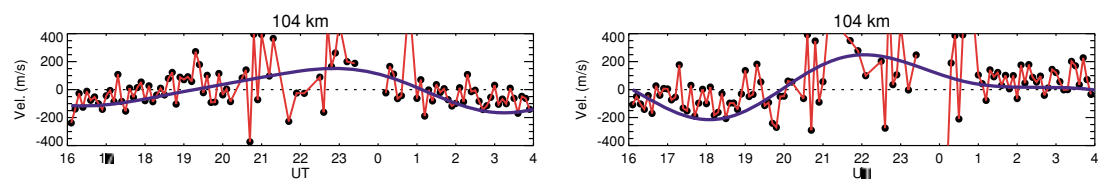

$104 \mathrm{~km}$
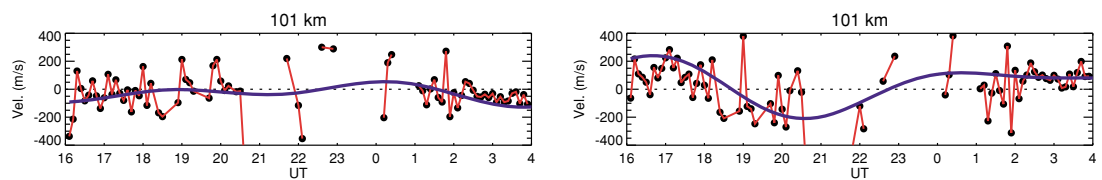

$101 \mathrm{~km}$
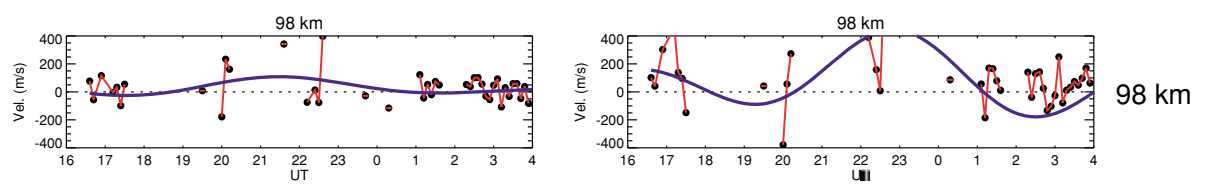

Fig. 3. Temporal variations of the derived meridional (left) and zonal (right) wind velocities are illustrated from 1600 UT on December 12 to 0400 UT on December 13, 2004 at seven heights.

method) needs spatial and temporal stability for $\sim 5 \mathrm{~min}$, which is not the case when an auroral arc passes overhead. Therefore, care is needed when dealing with such a data set.

Figure 4 shows temporal variations of the electric field, which were derived from ion velocities obtained at $282 \mathrm{~km}$ by using Eq. (1), for four nights of December 9, 10, 11, and 12, 2004. In general, the meridional component of the electric field is greater than that of the zonal component. The relatively strong amplitude of the southward electric field was observed every night and the amplitude became greater than $50 \mathrm{mV} \mathrm{m}^{-1}$ on occasion. The electric filed shows a tendency for the meridional component to turn from northward to southward about 2 hours earlier than the magnetic local midnight except for on December 12, 2004. The southward electric field lasted at least for four hours. These EISCAT radar observations indicate that most likely the thermosphere received energy and momentum from the magnetosphere through processes of Joule heating, particle heating, and ion-drag during the DELTA campaign period.

\section{Discussion}

\subsection{Day to day variability of the semidiurnal tide}

The day to day variability of the semidiurnal tide is generally thought to be significant in the lower thermosphere.
Here we investigate the day to day variation from December 9 to 12,2004 . Figure 5 shows altitude profiles of the semidiurnal tidal amplitude of meridional (solid circles) and zonal (open circles) components, as well as their corresponding phases (local time of maximum) in the height region from 70 to $110 \mathrm{~km}$ using MF and EISCAT radar observations during a four day period. Owing to poor data quality, the data for December 5 and 13 are not presented. Moreover, data at a height of $95 \mathrm{~km}$ for December 9-12 and data at heights of 98 and $101 \mathrm{~km}$ on December 12 are removed due to poor quality. Horizontal bars associated with each circle denote error values $(2 \sigma)$. The error value was calculated by the way shown by Nozawa and Brekke (1995). Above 95 $\mathrm{km}$, the semidiurnal tide is derived from the $12 \mathrm{hr}$ length of the EISCAT wind data. The Lomb-Scargle periodogram method, which is based on least-squares frequency analysis of unequally spaced data (cf. Hocke, 1998), was applied to derive the tidal components. EISCAT wind data above 110 $\mathrm{km}$ were not presented since the diurnal tidal component would not be negligibly small. At and below $91 \mathrm{~km}$, data values from the MF radar wind observations are presented. For the tidal analysis of the MF radar wind data, we used a $24 \mathrm{hr}$ interval for the wind data, which contained wind data between 6 hrs before and after the corresponding EISCAT 
North
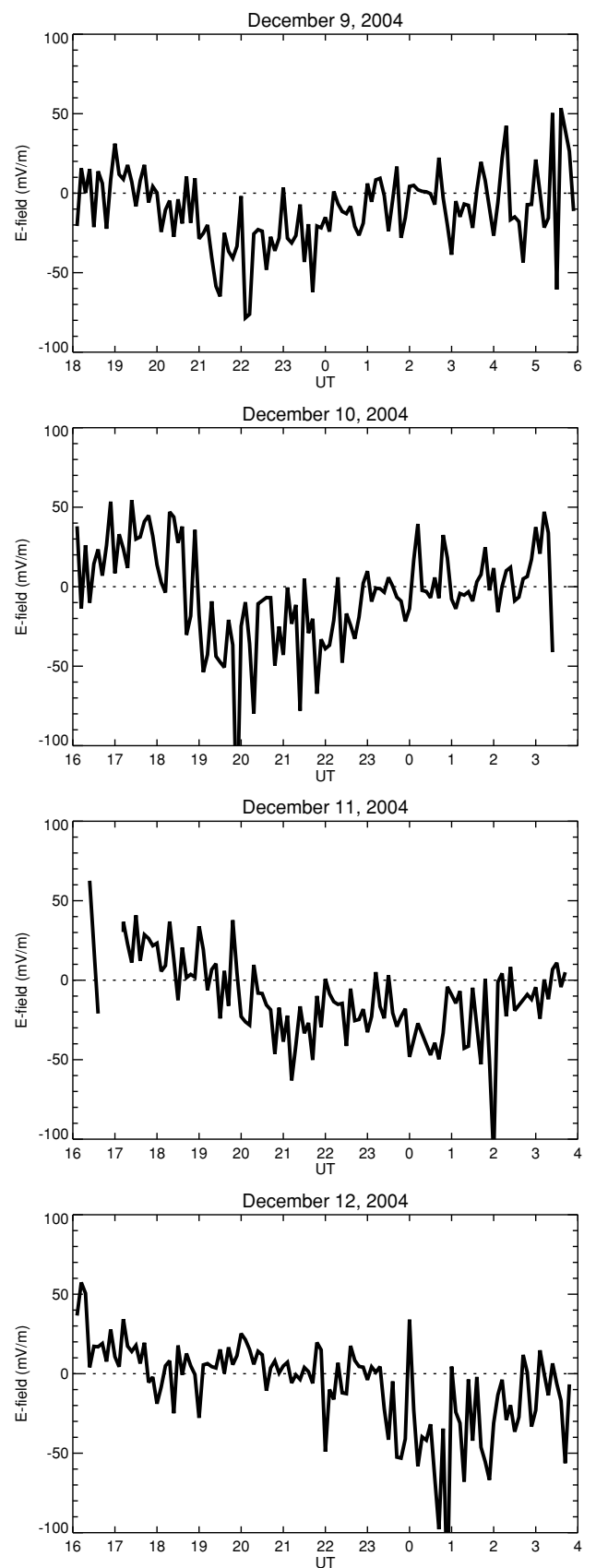

East
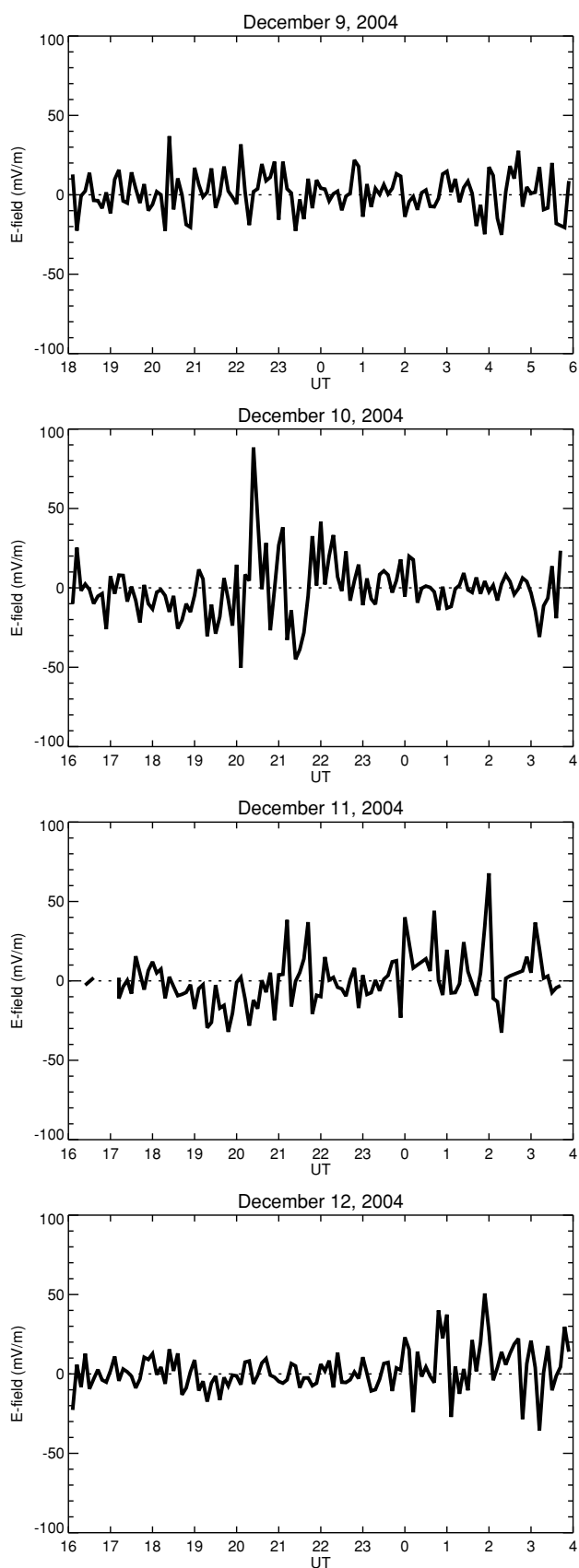

Fig. 4. Temporal (UT) variations of the electric field for meridional (left) and zonal (right) components for four days: December 9, 10, 11, and 12, 2004.

operational interval. Here we assume there is no bias due to difference of the radars based on the work by Nozawa et al. (2002).

Altitude profiles of the semidiurnal amplitude for December 9 and 10 exhibit similar features: the amplitude tends to increase with increasing altitude in the upper mesosphere and maximizes at $97-103 \mathrm{~km}$ in the lower thermosphere. The peak values of the amplitude are, however, different each other, and the altitude at which the amplitude maximizes is slightly different. The zonal amplitude on December 11 grows with increasing altitude and it exhibits a similar feature to those of December 9 and 10. It maximizes at $107 \mathrm{~km}$ with a value of $\sim 160 \mathrm{~m} \mathrm{~s}^{-1}$, where it is higher than those of the other two days. The meridional amplitude on December 11 exhibits a tendency to increase with increasing altitude from 73 to $91 \mathrm{~km}$, while it is almost constant between 101 and $110 \mathrm{~km}$. Corresponding phase values for both horizontal components for the 3 days of December 9-11 exhibit smoothed variations with altitudes from 76 to $110 \mathrm{~km}$. Differences of phase values above $76 \mathrm{~km}$ on December 10 and 11 are generally within $\sim 2$ hours for the meridional and zonal components. Phase values for December 9 differ by $2-4$ hrs in the lower thermosphere from those of the other two cases and shifted to later hours than those of the others. The vertical wavelength is estimated to be $\sim 35 \mathrm{~km}$ for the meridional and zonal components for the 

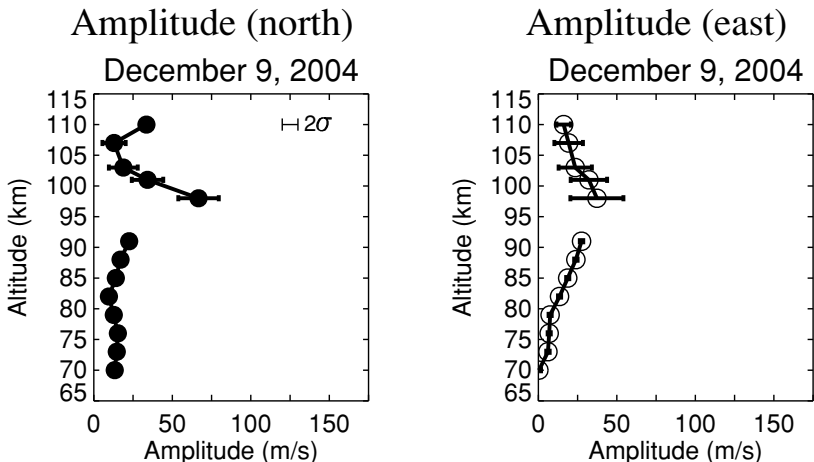

Phase

December 10, 2004
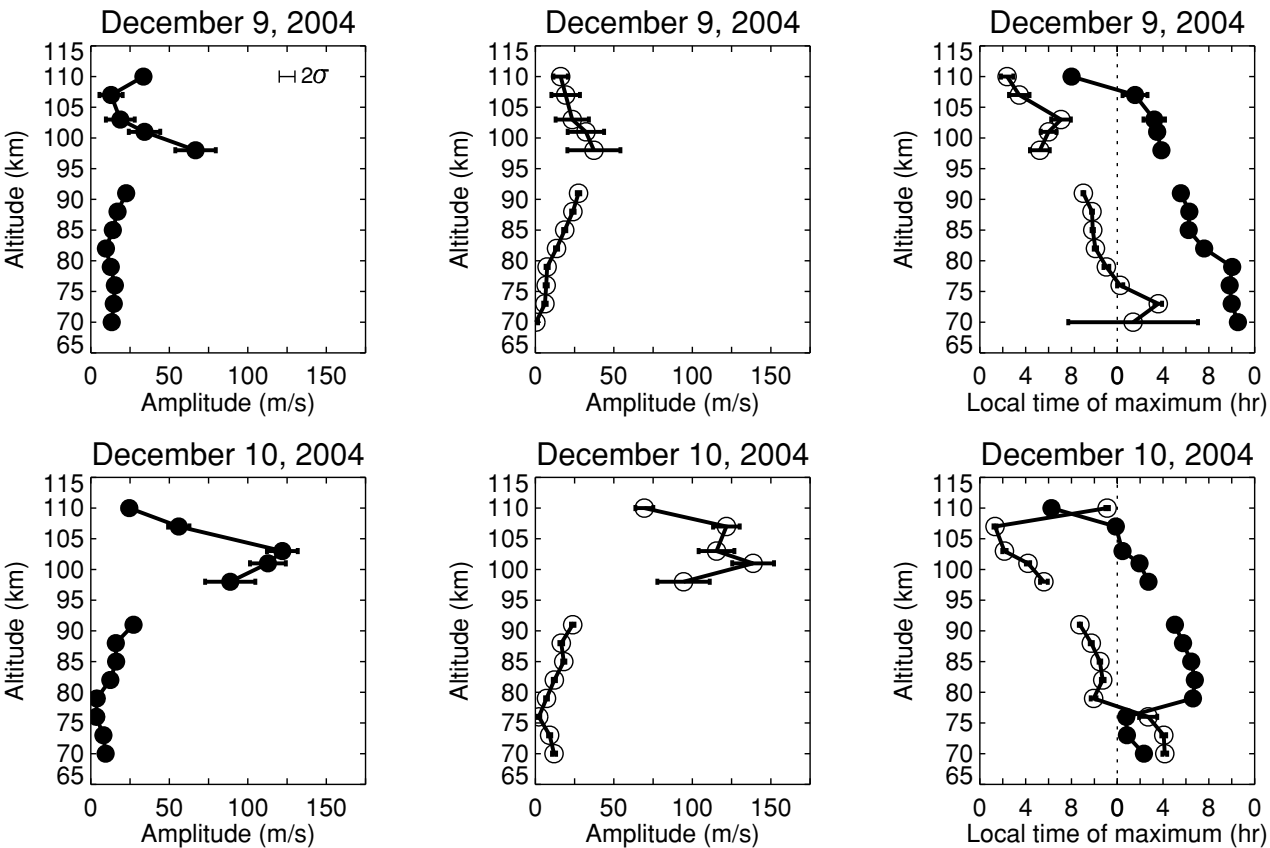

December 11, 2004
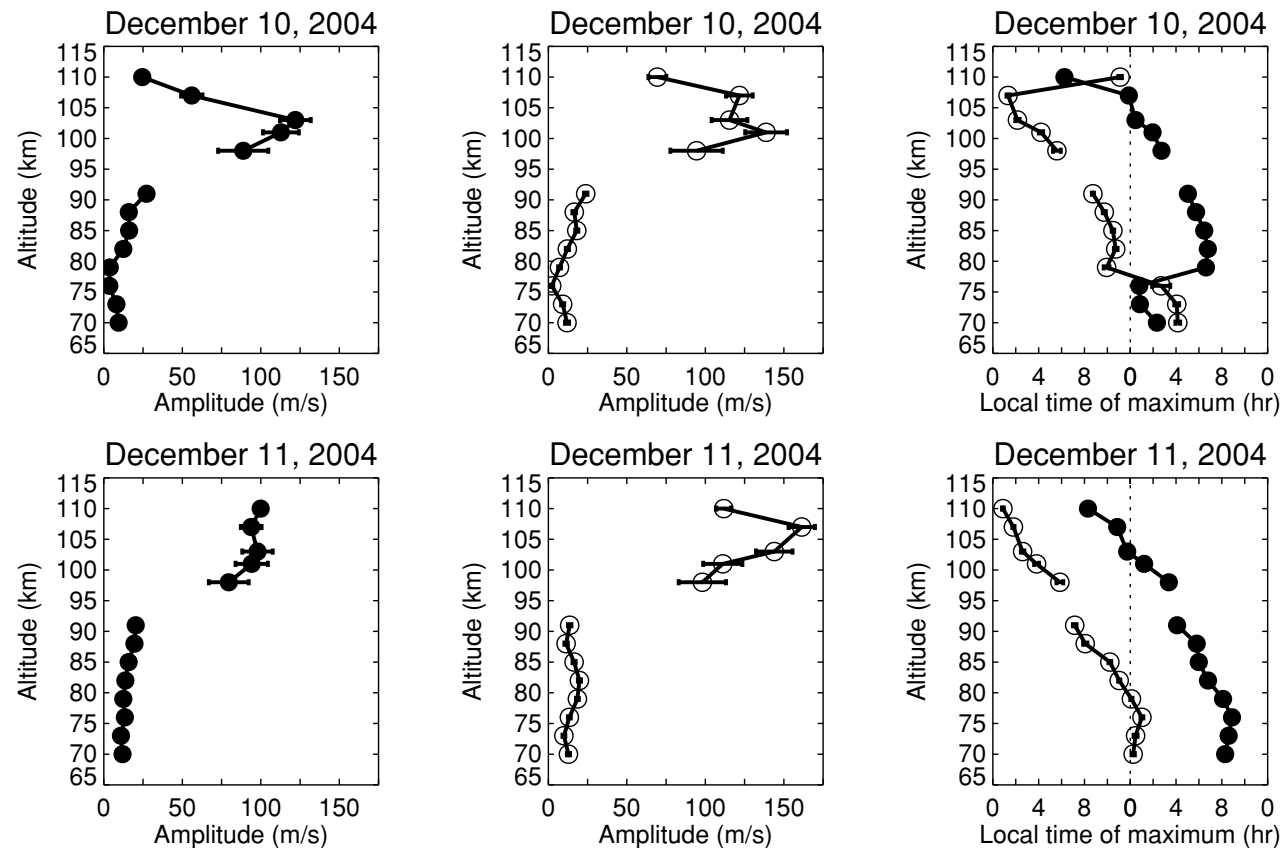

December 12, 2004
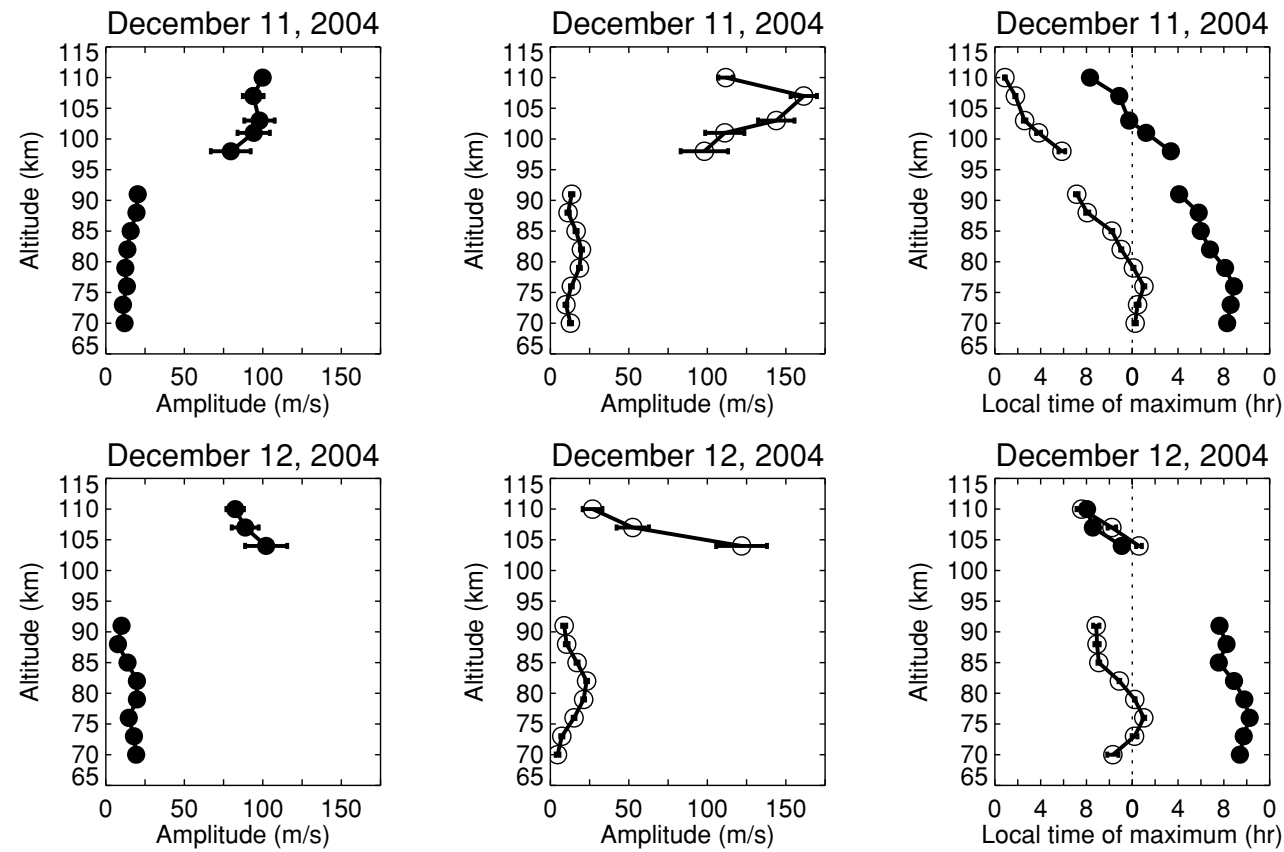

Fig. 5. Altitude profiles of the semidiurnal tidal meridional amplitude (left), zonal amplitude (middle), and corresponding phases (right). Meridional and zonal components are shown by closed and open circles with two sigma error bars.

three days, although the altitude profile of the zonal component on December 9 in the lower thermosphere is a bit distorted. With an estimated vertical wavelength of $\sim 35 \mathrm{~km}$, it would be associated in classical tidal theory with the migrating $(2,6),(2,5)$ or $(2,4)$ modes (e.g., Virdi et al., 1986; Forbes, 1995).

The meridional and zonal amplitudes of December 12 exhibit relatively similar features in the lower thermosphere compared to those for the other 3 days. The tidal values are difficult to derive below $104 \mathrm{~km}$ due to poor data quality. The amplitude on December 12 appears to maximize at or below $104 \mathrm{~km}$ with a value of $100-120 \mathrm{~m} \mathrm{~s}^{-1}$. In the mesosphere, the meridional amplitude shows a tendency of decreasing with increasing altitude, while the zonal amplitude maximizes at $82 \mathrm{~km}$ with a value of $23 \mathrm{~m} \mathrm{~s}^{-1}$. The amplitude of both the horizontal components is small $(\sim 10$ $\mathrm{m} \mathrm{s}^{-1}$ ) at $91 \mathrm{~km}$. The corresponding phases of the meridional component seem to connect with each other between the EISCAT and MF radar observations. It should be noted that the zonal phase on December 12 exhibits a different feature from those of the other three days. There is no phase shift between meridional and zonal components in the lower thermosphere. Thus, it appears that the zonal winds were affected by some in situ forcing in the lower thermosphere.

For December 9-12, the maximum amplitude values as well as corresponding peak altitudes of the meridional and 
zonal amplitudes exhibit a day to day variability. The peak values of the zonal amplitude are larger than $150 \mathrm{~m} \mathrm{~s}^{-1}$ on December 10 and 11, while it is less than $50 \mathrm{~m} \mathrm{~s}^{-1}$ on December 9 . The difference between days is relatively small for the meridional amplitude. The peak altitude where the amplitude maximizes varies with time between $97 \mathrm{~km}$ and $107 \mathrm{~km}$ for the four days. On the other hand, the corresponding phases are relatively stable (generally within a few hours) over the four days. The vertical wavelengths of the meridional and zonal components are about $35 \mathrm{~km}$ over the four days except for the zonal component on December 12. By using data obtained with the EISCAT UHF radar for the $E$ region radar and rocket instability study (ERRRIS) campaign, Huuskonen et al. (1991) examined the variability of semidiurnal tides in the lower thermosphere $(100-140 \mathrm{~km})$ and concluded that the 2-day wave played a role in modulating the amplitude of the semidiurnal tide through the process of non linear wave-wave coupling in the mesosphere. It should be pointed out that although, as shown in Fig. 2, the Q2DW was observed at $82 \mathrm{~km}$ during the period, it is not found for the amplitude modulation of the semidiurnal tide with a period of 2 days. Auroral forcing effects (i.e., Joule and particle heating and ion drag) start playing a role at least above $107 \mathrm{~km}$ (cf., Nozawa et al., 2005). Since we used data at and below $110 \mathrm{~km}$, it can be concluded that from December 9 to 12 the semidiurnal tide is dominated by the upward propagating component from the lower/middle atmosphere, and its amplitude exhibits a day-to-day variation. In contrast, the corresponding phase is relatively stable over the four days.

\subsection{Comparison of neutral/ion temperatures}

Figure 6(a) illustrates comparison of neutral/ion temperatures: ion temperature (solid circles) by EISCAT, derived neutral temperature (open circles) by EISCAT, modeled neutral temperature by MSIS90 model (thick dashed line), neutral temperature by Nitrogen Temperature instrument (NTV) (triangles) onboard the DELTA rocket. NTV (Kurihara et al., 2003) values are averaged every $1 \mathrm{~km}$ in altitude. The rocket was launched at 0033:00 UT on December 13,2004 at Andenes $\left(69.3^{\circ} \mathrm{N}, 16.22^{\circ} \mathrm{E}\right)$, and three representative positions from the rocket trajectory are tabulated in Table 3. The rocket reached an altitude of 106.7 $\mathrm{km}$ at 0034:40 UT, $140 \mathrm{~km}$ (apogee) at 0036:04 UT, and $105.3 \mathrm{~km}$ at 0037:30 UT. The rocket trajectory is separated by $\sim 100 \mathrm{~km}$ west from the EISCAT radar location. It should be kept in mind that the EISCAT data presented in Fig. 6 were obtained at the field-aligned position at Troms $\emptyset$ $\left(69.6^{\circ} \mathrm{N}, 19.2^{\circ} \mathrm{E}\right)$ from $0035: 15$ to $0036: 00 \mathrm{UT}$, while the rocket measurements were made over $\sim 3 \mathrm{~min}$ along the rocket trajectory. A map can be found in figure 2 by Abe et al. (2006a, this issue). Good agreement of NTV temperatures obtained when the rocket ascended and descended implies the presence of a relatively uniform structure of the neutral temperature in latitude over the rocket trajectory. The EISCAT ion temperature increases with increasing altitude and is higher by $200 \mathrm{~K}$ at and above $120 \mathrm{~km}$ than neutral temperature derived by NTV, but the shapes of those altitude profiles are similar. As shown in Fig. 5, since the strength of the electric field was $\sim 50 \mathrm{mV} \mathrm{m}^{-1}$ and the agreement is good below $110 \mathrm{~km}$, this difference above 110
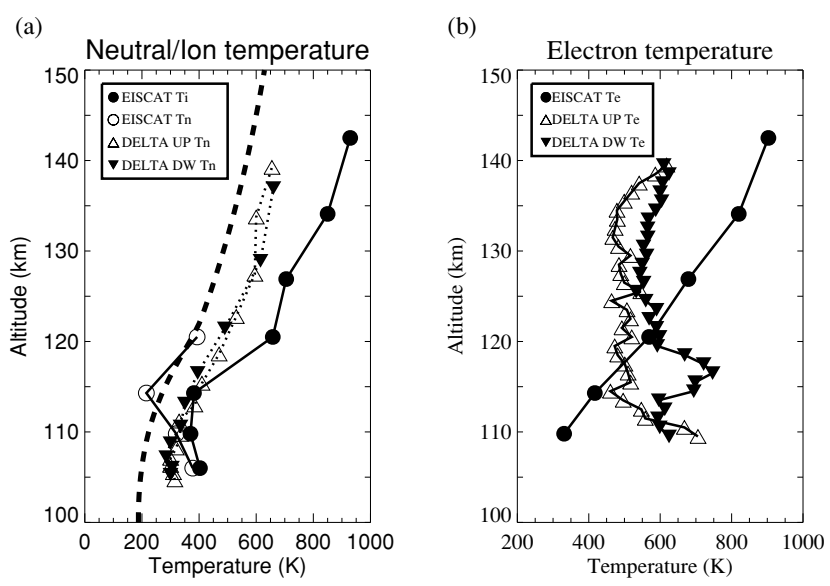

Fig. 6. (a) Altitude profiles of neutral and ion temperatures: ion temperatures by EISCAT (solid circles with solid line), neutral temperatures by EISCAT (open circles with solid line), neutral temperatures by NTV when the rocket ascended (open triangle with dotted line) and descended (reverse solid triangle with dotted line). Modeled neutral temperature by MSIS90 is also shown by thick-dashed line. NTV values are averaged by $1 \mathrm{~km}$ in altitude. (b) Altitude profiles of electron temperatures by EISCAT (solid circles with solid line), by FLP when the rocket ascended (open triangle with dotted line) and descended (reverse solid triangle with dotted line). FLP values are averaged by $1 \mathrm{~km}$ in altitude.

$\mathrm{km}$ is probably caused by Joule Heating. Thus, we can conclude that a good agreement is found qualitatively between the neutral temperature by NTV and the ion temperature by EISCAT radar.

In order to compare the neutral temperature more directly, we derived the neutral temperature from the EISCAT radar measurements. Under the assumption that the viscous heating, heat advection, heat conduction, frictional heating between ions and electrons and the heat exchange between ions and electrons are neglected, the neutral temperature can be derived by using the steady-state ion energy equation as follows:

$$
T_{n}=T_{i / /}-\beta_{/ /} \frac{\mathrm{m}_{\mathrm{n}}}{2 k_{b}}(\mathbf{v}-\mathbf{u})^{2}
$$

where $T_{n}$ is the neutral temperature, $T_{i / /}$ is the ion temperature measured along the local geomagnetic field line, $m_{n}$ is the neutral mass and $k_{b}$ is the Boltzmann's constant. The parameter $\beta_{/ /}$is the partition coefficient for the parallel ion temperatures and uses a value of 0.54 (cf. Maeda et al., 2005). At and below $110 \mathrm{~km}$, the contribution of the second term on the right side in Eq. (3) is small due to more abundant neutral particles compared to ion particles. Thus, at and below $110 \mathrm{~km}$, good agreement is found for neutral temperatures measured by NTV and derived by EISCAT radar observations. At $118 \mathrm{~km}$, relatively good agreement is found for the neutral temperatures between EISCAT and rocket measurements. However, at $114 \mathrm{~km}$, the neutral temperature derived by the EISCAT observations is lower by $\sim 200 \mathrm{~K}$ than that measured by the rocket. In the first place, this discrepancy would be attributed to uncertainties of EISCAT radar values of the neutral wind and ion velocity at $114 \mathrm{~km}$ (see Fig. 3), since the auroral arc passed by the beams and the strong electric field was present.

When we compare the neutral temperature derived by 
EISCAT with that predicted by the MSIS90 model, a bit surprisingly, at 114 and $118 \mathrm{~km}$, a good agreement is found between the EISCAT and MSIS90 model values. Between 110 and $143 \mathrm{~km}$, the error values of the ion temperature are smaller than $40 \mathrm{~K}$. However, below $110 \mathrm{~km}$ due to low electron density the EISCAT radar data suffer from larger uncertainties. At $106 \mathrm{~km}$ the error value of the ion temperature is $\sim 85 \mathrm{~K}$. Considering the error values, we could conclude that the neutral temperature derived by EISCAT is in fairly good agreement with that from the MSIS90 model. A detailed comparison between the neutral temperatures by NTV and from the MSIS90 model is given in Kurihara et al. (this issue). This paper is confined to these comparison results. These comparisons suggest that additional studies are required to conclude which neutral temperature is most reliable.

\subsection{Comparison of electron temperatures}

There are several studies which have compared the electron temperature in the $F$ region measured by Incoherent Scatter radar and instruments onboard rockets (cf. Svenes et al., 1992; Oyama and Schlegel, 1988), while there are few studies which have been conducted in the E-region. Thus, it is worthwhile to compare electron temperature measured by the EISCAT radar and the Fast Langmuir Probe (FLP) (Brace, 1998) onboard the DELTA rocket. Figure 6(b) compares electron temperatures by EISCAT (solid circles) and by FLP (triangles). More detailed presentations and discussions in terms of the electron temperature by FLP are given by Abe et al. (2006b, this issue). In Fig. 6(b), the FLP values are averaged every $1 \mathrm{~km}$ in altitude. The electron temperature by the EISCAT radar increases with increasing altitude similar to the ion temperature. This altitude profile is reasonable when the aurora particle precipitation occurs. In contrast, the electron temperature by FLP is relatively constant with a height between 120 and $140 \mathrm{~km}$. According to aurora images taken at Kilpisjävi $\left(69.0^{\circ} \mathrm{N}, 20.9^{\circ} \mathrm{E}\right)$ (see figure 1 by Kurihara et al., this issue), an auroral arc moved from west to east and passed by the field-of-view of the EISCAT radar. During the measurement at the fieldaligned position from 0035:15 to 0036:00 UT, the EISCAT observed the auroral arc most of the time. On the other hand, the rocket flew north of the auroral arc and the auroral arc was out of view most of the time except at the beginning of the flight. The electron temperature by EISCAT is higher and lower than that by FLP above and below 120 $\mathrm{km}$, respectively. Above $120 \mathrm{~km}$, since the EISCAT radar captured the auroral arc (i.e., the effect of particle heating) and the rocket was not in the auroral arc, this result is reasonable. The temperature enhancement by FLP at $110 \mathrm{~km}$ when the rocket ascended can be interpreted by the heating effect of an instability due to the presence of the strong electric field, probably the Farley-Buneman instability (cf. StMaurice et al., 1981). On the other hand, the enhancement of the electron temperature below $120 \mathrm{~km}$ when the rocket descended is hard to understand. The electron temperature by FLP shows an enhancement at $116 \mathrm{~km}$ with a peak value of $\sim 800 \mathrm{~K}$. There should be a heating process occurring in the ionosphere where the rocket passed by. Since the FarlyBuneman instability works more effectively at and below $110 \mathrm{~km}$, the presence of the peak altitude of $116 \mathrm{~km}$ cannot be explained well. One possible explanation is that this altitude profile is contaminated by the spatial (latitudinal) variation of the electron temperature. To conclude, there is poor agreement found in electron temperatures between EISCAT and rocket measurements. In other words, this comparison result confirms that the electron temperature is influenced significantly by local heating processes.

\section{Summary and conclusions}

We conducted the EISCAT radar observations on December 5 and from December 8 to December 13, 2004 with a beam-scanning mode at Troms $\varnothing\left(69.6^{\circ} \mathrm{N}, 19.2^{\circ} \mathrm{E}\right)$. Except for December 8 with a 2-hr interval operation, we operated the EISCAT UHF radar for 12 hour intervals everyday. From the EISCAT data, we derived the semidiurnal tidal amplitude and phases for 5 days. EISCAT observations showed that the magnetospheric activity was high during the period from December 5 to 13 except for the night of December 13, although the daily $A p$ index was within the range of 8 to 29. The near real-time display of the EISCAT radar data at Andenes $\left(69.3^{\circ} \mathrm{N}, 16.22^{\circ} \mathrm{E}\right)$ was actually used to indicate suitable launch conditions for the DELTA rocket. The rocket was launched successfully at 0033:00 UT on December 13, 2004 at Andenes. The day-to-day variability of the semidiurnal tide was investigated and was found to be prominent for the amplitude and its peak altitude over four nights from December 9 to 12, 2004. In contrast, the corresponding phase was relatively stable (generally within a few hours) over the four days except for the zonal component on December 12. The Q2DW was observed at 82 $\mathrm{km}$ in the mesosphere during the period, but the semidiurnal amplitude in the lower thermosphere did not exhibit a clear 2-day modulation. Comparison of neutral temperatures measured by NTV onboard the DELTA rocket and ion temperature by the EISCAT UHF radar show reasonable agreement. In contrast, the electron temperature measured by FLP onboard the DELTA rocket and the EISCAT radar disagree with each other.

Acknowledgments. S.N. thanks Dr. K. Hocke for letting us use his Lomb-Scargle periodogram method routines. We wish to thank the EISCAT staff. EISCAT is jointly funded by the Particle Physics and Astronomy Research Council (U.K.), Centre National de la Recherche Scientifique (France), Max-Planck Gesellschaft (F.R.G.), Suomen Akatemia (Finland), National Institute of Polar Research (Japan), Norges Forskningsråd (Norway), and Naturvetenskapliga Forskningstrådet (Sweden). This research has been partly supported by Grant-in-Aid for Scientific Research B (16340146 and 17340145) by the Ministry of Education, Science, Sports and Culture, Japan, and a grant from the Ministry of Education, Culture, Sports, Science and Technology, Japan (Dynamics of the Sun-Earth-Life Interactive System, No. G-4, the 21st Century COE Program). This research has also been supported by Norges Forskningstråd through grant 159524/V30.

\section{References}

Abe, T., J. Kurihara, N. Iwagami, S. Nozawa, Y. Ogawa, R. Fujii, H. Hayakawa, and K. Oyama, Dynamics and energetics in the lower thermosphere in aurora (DELTA)—Japanese sounding rocket campaign, Earth Plants Space, 58, this issue, 1165-1171, 2006a.

Abe, T., K. Oyama, and A. Kadohata, Electron temperature variation associated with the auroral energy input during the DELTA campaign, Earth Planets Space, 58, this issue, 1139-1146, 2006b.

Azeem, S. M. I. and R. M. Johnson, Lower thermospheric neutral winds at 
Søndre Strømfjord: A seasonal analysis, J. Geophys. Res., 102, 7379_ 7397, 1997.

Brace, L. H., Langmuir probe measurements in the ionosphere, in $\mathrm{Mea}$ surement Techniques in Space Plasmas: Particles, edited by R. F. Pfaff, J. E. Borovsky, and D. T. Young, pp. 23-35, American Geophysical Union Monograph 102, 1998.

Brekke, A., J. R. Doupnik, and P. M. Banks, A preliminary study of the neutral wind in the aurora $E$ region, J. Geophys. Res., 78, 8235-8250, 1973.

Collis, P. N., EISCAT data base for ionospheric modelling: F-region and topside ionosphere, Adv. Space Res., 102(1), 37-46, 1995.

Comfort, R. H., S. T. Wu, and G. R. Swenson, An analysis of auroral $E$ region neutral winds based on incoherent scatter radar observations at Chatanika, Planet Space Sci., 24, 541-560, 1976.

Folkestad, K., T. Hagfors, and S. Westerlund, EISCAT: An updated description of technical characteristics and operational capabilities, Radio Sci., 18, 867-879, 1983.

Forbes, J. M., Tidal and Planetary Waves, The Upper Mesosphere and Lower Thermosphere: A Review of Experiment and Theory in Geophysical Monograph, edited by R. M. Johnson and T. L. Killeen, 356 pp, American Geophysical Union, 67-87, 1995.

Hall, C. M., The Ramfjordmoen MF radar $\left(69^{\circ} \mathrm{N}, 19^{\circ} \mathrm{E}\right)$ : Application development 1990-2000, J. Atmos. Sol.-Terr. Phys., 63, 171-179, 2001.

Hedin, A. E., Extension of the MSIS thermosphere model into the middle and lower atmosphere, J. Geophys. Res., 96, 1159-1172, 1991.

Hocke, K., Phase estimation with the Lomb-Scargle periodogram method, Ann. Geophys., 16, 356-358, 1998.

Huuskonen, A., T. S. Virdi, G. O. L. Jones, and P. J. S. Williams, Observations of day-to-day variability in the meridional semi-diurnal tide at $70^{\circ} \mathrm{N}$, Ann. Geophys., 9, 407-415, 1991.

IAGA Division I Working Group 1, International geomagnetic reference field revision 1987, J. Geomag. Geoelectr., 39, 773-779, 1987.

Johnson, R. M. and T. S. Virdi, High-latitude lower thermospheric neutral winds at EISCAT and Sondrestrom during LTCS 1, J. Geophys. Res., 96, 1099-1116, 1991.

Johnson, R. M., V. B. Wickwar, R. G. Roble, and J. G. Luhmann, Lowerthermospheric winds at high latitude: Chatanika radar observations, Ann. Geophys., 5, 383-404, 1987.

Kurihara, J., K.-I. Oyama, K. Suzuki, and N. Iwagami, Vibrationalrotational temperature measurements of $\mathrm{N}_{2}$ in the lower thermosphere by the rocket experiment, Adv. Space Res., 32, 725-729, 2003.

Kurihara, J., T. Abe, K. Oyama, E. Griffin, M. Kosch, A. Aruliah, K. Kauristie, Y. Ogawa, S. Komada, and N. Iwagami, Observations of the lower thermospheric neutral temperature and density in the DELTA campaign, Earth Planets Space, 58, this issue, 1123-1130, 2006.

Larsen, M. F., A. B. Christensen, and C. D. Odom, Observations of unstable atmospheric shear layers in the lower E region in the postmidnight auroral oval, Geophys. Res. Lett., 24, 1915-1918, 1997.

Larsen, M. F., S. Fukao, M. Yamamoto, R. Tsunoda, K. Igarashi, and T. Ono, The SEEK Chemical Release Experiment: Observed neutral wind profile in a region of sporadic E, Geophys. Res. Lett., 25, 1789-1792, 1998.
Maeda, S., S. Nozawa, H. Fujiwara, and Y. Ogawa, Comparative study of the high-latitude E-region ion and neutral temperatures in the polar cap and the auroral region derived from the EISCAT radar observations, $J$. Geophys. Res., 110, A08301, 10.1029/2004JA010893, 2005.

Nozawa, S. and A. Brekke, Studies of the $E$ region neutral wind in the disturbed auroral ionosphere, J. Geophys. Res., 100, 14,717-14,734, 1995.

Nozawa, S. and A. Brekke, Studies of the auroral $E$ region neutral wind through a solar cycle: Quiet days, J. Geophys. Res., 104, 45-66, 1999.

Nozawa, S., A. Brekke, A. Manson, C. Hall, C. Meek, K. Morise, S. Oyama, K. Dobashi, and R. Fujii, A comparison study of the auroral lower thermospheric neutral winds derived by the EISCAT UHF radar and Troms $\emptyset$ medium frequency radar, J. Geophys. Res., 107, 10.1029/ 2000JA007581, SIA29-1-SIA29-20, 2002.

Nozawa, S., A. Brekke, S. Maeda, T. Aso, C. Hall, Y. Ogawa, S. Buchert, J. Röttger, A. Richmond, R. Roble, and R. Fujii, Mean winds, tides and quasi-2 day wave in the polar lower thermosphere observed in EISCAT eight day run data in November 2003, J. Geophys. Res., 110, doi:10. 1029/2005JA011128, 2005.

Oyama, K. and K. Schlegel, Observation of electron temperature anisotropy in the ionosphere: A review, Ann. Geophys., 6, 389-400, 1988.

Parish, H. F., R. L. Walterscheid, P. W. Jones, and L. R. Lyons, Simulations of the thermospheric response to the diffuse aurora using a threedimensional high-resolution model, J. Geophys. Res., 108, doi:10.1029/ 2002JA009610, 2003.

Rino, C. L., A. Brekke, and M. J. Baron, High-resolution auroral zone E region neutral wind and current measurements by incoherent scatter radar, J. Geophys. Res., 82, 2295-2304, 1977.

Schunk, R. W. and J. C. G. Walker, Theoretical ion densities in the lower ionosphere, Planet. Space Sci., 21, 1875-1896, 1973.

St.-Maurice, J.-P., K. Schlegel, and P. M. Banks, Anomalous heating of the polar E region by unstable plasma waves, 2. Theory, J. Geophys. Res., 86, 1453-1462, 1981.

Svenes, K. R., B. N. Maehlum, J. Trøim, G. Holmgren, R. L. Arnoldy, U. P. Løvhaug, M. T. Rietveld, and C. Hall, Combined rocket and ground observations of electron heating in the ionospheric $F$-layer, Planet. Space Sci., 40, 901-912, 1992.

Virdi, T. S., G. O. L. Jones, and P. J. S. Williams, EISCAT observations of the E-region semidiurnal tide, Nature, 324, 354-356, 1986.

Williams, P. J. S. and T. S. Virdi, EISCAT observations of tidal modes in the lower thermosphere, J. Atoms. Terr. Phys., 51, 569-577, 1989.

Yamamoto, M., T. Ono, H. Oya, R. T. Tsunoda, M. F. Larsen, S. Fukao, and M. Yamamoto, Structures in sporadic-E observed with an impedance probe during the SEEK campaign: Comparisons with neutral-wind and radar-echo observations Geophys. Res. Lett., 25, 1781-1784, 1998.

S. Nozawa (e-mail: nozawa@stelab.nagoya-u.ac.jp), Y. Ogawa, A. Brekke, T. Tsuda, C. M. Hall, H. Miyaoka, J. Kurihara, T. Abe, and R. Fujii 